\title{
Performance Estimation for Concretes Made with Recycled Aggregates of Construction and Demolition Waste of Some Brazilian Cities
}

\author{
Antonio Eduardo Bezerra Cabral ${ }^{\text {**, Valdir Schalch }}$, \\ Denise Carpena Coitinho Dal Molin', José Luis Duarte Ribeiro \\ ${ }^{a}$ Departamento de Engenharia Estrutural e Construção Civil - DEECC, Centro de Tecnologia, \\ Universidade Federal do Ceará - UFC, Campus do Pici, Bloco 710, Pici, \\ CEP 60455-760, Fortaleza, CE, Brasil \\ ${ }^{\mathrm{b}}$ Departamento de Hidraúlica e Saneamento - SHS, Escola de Engenharia de São Carlos - EESC, \\ Universidade de São Paulo - USP, Av. Trabalhador Sãocarlense, \\ 400, Centro, CEP 13566-590, São Carlos, SP, Brasil \\ ${ }^{\mathrm{c}}$ Núcleo Orientado para a Inovação da Edificação - NORIE, Escola de Engenharia, \\ Universidade Federal do Rio Grande do Sul-UFRGS, Av. Osvaldo Aranha, \\ 99, CEP 90035-190, Porto Alegre, RS, Brasil
}

Received: January 22, 2011; Revised: July 24, 2012

\begin{abstract}
The aim of this paper is to verify the influence of composition variability of recycled aggregates (RA) of construction and demolition wastes (CDW) on the performance of concretes. Performance was evaluated building mathematical models for compressive strength, modulus of elasticity and drying shrinkage. To obtain such models, an experimental program comprising 50 concrete mixtures was carried out. Specimens were casted, tested and results for compressive strength, modulus of elasticity and drying shrinkage were statistically analyzed. Models inputs are CDW composition observed at seven Brazilian cities. Results confirm that using RA from CDW for concrete building is quite feasible, independently of its composition, once compressive strength and modulus of elasticity still reached considerable values. We concluded the variability presented by recycled aggregates of CDW does not compromise their use for concrete building. However, this information must be used with caution, and experimental tests should always be performed to certify concrete properties.
\end{abstract}

Keywords: $C D W$, waste variability, recycled aggregate, concrete

\section{Introduction}

Due to improper managed, construction and demolition waste $(\mathrm{CDW})$ has been causing severe problems to the population, once they are co-responsible for negative impacts, as inundations, because of the streams' siltation, damages to the landscape, obstruction of roads, proliferation of diseases, among other damages to the human health.

A point that demonstrates the relevance of CDW is its improvement in the urban solid wastes. Exemplifying, data from Salvador City, in Brazil, shows that from 1993 to 2000 the proportion of CDW on urban solid waste collected by the municipality ${ }^{1}$ increased from $30.1 \%$ to $49.8 \%$.

The same trend seems to hold in other regions of the world, once in Hong Kong the construction industry produces approximately 37,100 tons of wastes everyday, which corresponds to four times the volume of domestic wastes ${ }^{2}$.

Several researches point that CDW are now around $50 \%$ of the urban solid wastes produced in Brazilian cities, with an average generation around 0.52 tons/inhabitant. year $^{3-6}$. In European Union, there is no consensus about CDW generation but it represents approximately $22 \%-49 \%$

*e-mail: eduardo.cabral@ufc.br of the total waste generation at European cities, totalizing 450-970 million tonnes of CDW generated per year, which corresponds to 0.9-2.0 tonne/inhabitant.year, in average ${ }^{7-9}$. However, France and Luxembourg generate 5.5 and 15 tonnes/inhabitant.year, respectively, Germany and Ireland generate between 2 and 4 tonnes/inhabitant.year, while the rest of the European countries generate between 0.2 tonnes/ inhabitant.year (Norway) and 1.9 tonnes/inhabitant.year (United Kingdom $)^{9}$. In the United States, the generation of CDW during $90^{\text {th }}$ years was 0.43 tonne/inhabitant.year ${ }^{10}$ and in 2002 it was estimated as 2.0-2.57 tonnes/inhabitant.year ${ }^{11}$.

One of the main characteristics of CDW is its heterogeneity. The composition of CDW depends on many variables, among which we highlight: the geographical area where it is produced, the season of the year, the type of construction, among others. When originated from construction sites, the waste composition depends on the work stage, once in the concrete casting stage there is a larger incidence of concrete fragments, steel and timber formwork, while in the completion stage there is a predominance of mortar, bricks, tiles and ceramic fragments ${ }^{2}$. In case of reform work, a larger incidence of ceramic materials, wood, natural rocks, glasses, metals and plastics are usual ${ }^{12}$. 
In Brazil, it is considered that on average $65 \%$ of the CDW are mineral, $13 \%$ wood, $8 \%$ plastics and $14 \%$ other materials. Construction industry is responsible for the generation of $20 \%$ to $25 \%$ of CDW and the remaining percentage comes from reforms and of auto-constructions works ${ }^{13}$.

For demolition works, waste characteristics also vary according to the structure to be demolished and the technique used. However, in a general way, demolition wastes consist of a high percentile of inert material, as brick, sand and concrete. Metals, wood, papers, glass, plastics and other materials also appear, but in smaller percentage ${ }^{2}$.

Table 1 presents the composition of CDW for different Brazilian cities. It can be observed that for all cities mortar, concrete and ceramic material correspond together more than $60 \%$. That proportion is similar on other regions of the world, once in Europe, those components still correspond to something around $50 \%$ of the total $\mathrm{CDW}^{14}$. In Malaysia, concrete and aggregates wastes and concrete and ceramic blocks correspond to $67 \%$ of wasted materials ${ }^{15}$ while in Kuwait, concrete debris and ceramic blocks correspond to $60 \%{ }^{16}$.

A research accomplished in agreement by eleven Brazilian universities measured the losses of construction materials in almost a hundred construction sites. Results of this research confirm values mentioned previously, once on average, $9 \%$ of pre-cast concrete, $17 \%$ of blocks and bricks, $85.5 \%$ of cement in plaster services, $79 \%$ of cement in underlayment services, $22 \%$ of ceramic plates to floors, $16 \%$ of ceramic plates to walls and $12 \%$ of ceramic plates to facade were wasted ${ }^{23}$.

The data mentioned previously showed concrete, mortar and ceramic materials as the main components of construction wastes. Those data confirm the Brazilian constructive culture, where the largest losses happen in concrete casting, brickwork, plastering and covering. These materials are also the most wasted in construction sites of European Union. According to Van Acker ${ }^{24}$, the mineral part of European CDW is composed approximately by $41 \%$ of concrete, $40 \%$ of masonry and $7 \%$ of ceramic and tiles.

In some urban areas there is a critical shortage of natural aggregates for concrete production, and, at the same time, in these areas there is an increase of CDW volumes. The recycling of CDW and its reuse in construction as an alternative raw material is a solution for the many problems it may represent and also for a reduction of the extraction of natural aggregates ${ }^{25,26}$.
However, CDW composition variability has been pointed out as one of the restrictive factors for CDW recycling expansion, since the composition influences recycled aggregate concretes' performance.

In this context, the objective of this article is to verify the influence of composition variability of recycled aggregate of CDW in the performance of concretes, evaluated through its compressive strength, modulus of elasticity and drying shrinkage.

\section{Research Method}

Modeling the behavior of concrete properties, such as compressive strength, modulus of elasticity, tension strength, among other, already was a study object of some researchers ${ }^{19,22,27}$. However, the models proposed by such authors are specific for some composition and do not contemplate the natural variability of CDW.

In this study, to consider the variability a fractional project of experiments ${ }^{28}$ was carried out. Factors under investigation (independent variables) were type and content of fine aggregate (natural, recycled mortar, recycled concrete and recycled red ceramic), type and content of coarse aggregate (natural, recycled mortar, recycled concrete and recycled red ceramic) and water/cement ratio $(0.46,0.60$ and 0.74). Similar studies employing statistical tools were also conducted by other researches ${ }^{22,27,29}$.

For this study, 50 concretes mixtures were prepared (see Table 2) and for each mixture seven cylindrical specimens $(\varnothing=10 \mathrm{~cm} ; \mathrm{h}=20 \mathrm{~cm})$ and two prismatic specimens $(7,5 \mathrm{~cm} \times 7,5 \mathrm{~cm} \times 32,5 \mathrm{~cm})$ were casted. Cylindrical specimens were used to evaluate compressive strength ( $f_{c}$ ) and initial tangent modulus of elasticity $\left(\mathrm{E}_{\mathrm{c}}\right)$ at 28 days of age, while prismatic specimens were used for testing drying shrinkage $(\varepsilon)$ at 224 days of age. The tests were performed following the standard procedures NBR $5739^{30}$, NBR $8522^{31}$ and ASTM C $157^{32}$, respectively. Average results for each property are also shown in Table 2 .

Results were statistically analyzed using Statistica package 7.0 and models were built for each property. Nonlinear regression was used for building the models, which are presented in Equations 1, 2 and 3. Table 3 shows the terminology for independent and dependent variables used in models. Terms $b 1, b 2, a 1, a 2, a 3, a 4, a 5$ and $a 6$ are parameters estimated by the nonlinear regression routine.

Table 1. CDW composition observed in some Brazilian cities.

\begin{tabular}{|c|c|c|c|c|c|c|c|}
\hline Components & $\begin{array}{c}\text { São } \\
\text { Carlos/SP' } \\
(\%)\end{array}$ & $\begin{array}{c}\text { São } \\
\text { Paulo/SP18 } \\
(\%)\end{array}$ & $\begin{array}{c}\text { Porto } \\
\text { Alegre/RS } \\
(\%)\end{array}$ & $\begin{array}{c}\text { Ribeirão } \\
\text { Preto/SP } \\
(\%)\end{array}$ & $\begin{array}{c}\text { Salvador/BA } \\
(\%)\end{array}$ & $\begin{array}{c}\text { Campina } \\
\text { Grande/PB } \\
(\%)\end{array}$ & $\begin{array}{c}\text { Maceió/AL } \mathbf{L}^{22} \\
(\%)\end{array}$ \\
\hline Mortar & 63.67 & 25.2 & 44.2 & 37.4 & \multirow{2}{*}{53.0} & 28 & 27.82 \\
\hline Concrete & 4.38 & 8.2 & 18.3 & 21.1 & & 10 & 18.65 \\
\hline $\begin{array}{l}\text { Ceramic } \\
\text { materials }\end{array}$ & 29.09 & 29.6 & 35.6 & 20.8 & 9.0 & 34 & 48.15 \\
\hline $\begin{array}{l}\text { Polished } \\
\text { ceramic }\end{array}$ & 0.39 & - & 0.1 & 2.5 & 5.0 & 1 & 3.06 \\
\hline Rocks, Soils & 0.13 & 32 & 1.8 & 17.7 & 27.0 & 9 & - \\
\hline Others & 2.34 & 5 & - & 0.5 & 6.0 & 18 & 2.32 \\
\hline
\end{tabular}


Table 2. Concrete mixtures contemplated by the fractional factorial experiment and corresponding average values for compressive strength, modulus of elasticity and drying shrinkage results.

\begin{tabular}{|c|c|c|c|c|c|c|c|c|c|c|c|c|}
\hline \multirow{2}{*}{ Mix } & \multirow{2}{*}{ w/c ratio } & \multicolumn{4}{|c|}{ Coarse aggregate $(\%)$} & \multicolumn{4}{|c|}{ Fine aggregate $(\%)$} & \multirow{2}{*}{$\mathbf{f}_{\mathrm{c}, \mathrm{m}}(\mathrm{MPa})$} & \multirow{2}{*}{$\mathbf{E}_{c, m}(\mathbf{G P a})$} & \multirow{2}{*}{$\varepsilon_{224, \mathrm{~m}}\left(10^{-6}\right)$} \\
\hline & & $\mathbf{N}$ & RC & RRC & $\mathbf{R M}$ & $\mathbf{N}$ & $\mathbf{R C}$ & RRC & $\mathbf{R M}$ & & & \\
\hline 01 & 0.46 & 100 & 0 & 0 & 0 & 100 & 0 & 0 & 0 & 46.13 & 34.47 & 393 \\
\hline 02 & 0.74 & 100 & 0 & 0 & 0 & 0 & 0 & 100 & 0 & 34.42 & 20.62 & 777 \\
\hline 03 & 0.74 & 100 & 0 & 0 & 0 & 0 & 100 & 0 & 0 & 17.78 & 15.14 & 1538 \\
\hline 04 & 0.46 & 100 & 0 & 0 & 0 & 0 & 50 & 50 & 0 & 47.69 & 29.06 & 675 \\
\hline 05 & 0.74 & 0 & 0 & 0 & 100 & 0 & 0 & 0 & 100 & 15.73 & 11.85 & 1387 \\
\hline 06 & 0.46 & 0 & 0 & 0 & 100 & 0 & 0 & 50 & 50 & 31.11 & 16.70 & 1037 \\
\hline 07 & 0.46 & 0 & 0 & 0 & 100 & 0 & 50 & 0 & 50 & 25.96 & 15.31 & 1345 \\
\hline 08 & 0.74 & 0 & 0 & 0 & 100 & 0 & 33 & 33 & 33 & 19.12 & 14.47 & 1340 \\
\hline 09 & 0.46 & 0 & 0 & 100 & 0 & 0 & 0 & 0 & 100 & 24.13 & 13.47 & 1096 \\
\hline 10 & 0.74 & 0 & 0 & 100 & 0 & 0 & 0 & 50 & 50 & 18.62 & 11.83 & 1338 \\
\hline 11 & 0.74 & 0 & 0 & 100 & 0 & 0 & 50 & 0 & 50 & 14.67 & 10.64 & 1246 \\
\hline 12 & 0.46 & 0 & 0 & 100 & 0 & 0 & 33 & 33 & 33 & 26.88 & 12.61 & 1006 \\
\hline 13 & 0.74 & 0 & 0 & 50 & 50 & 100 & 0 & 0 & 0 & 18.34 & 15.42 & 1000 \\
\hline 14 & 0.46 & 0 & 0 & 50 & 50 & 0 & 0 & 100 & 0 & 35.48 & 15.83 & 1040 \\
\hline 15 & 0.46 & 0 & 0 & 50 & 50 & 0 & 100 & 0 & 0 & 30.12 & 16.29 & 900 \\
\hline 16 & 0.74 & 0 & 0 & 50 & 50 & 0 & 50 & 50 & 0 & 19.33 & 14.28 & 1384 \\
\hline 17 & 0.46 & 0 & 100 & 0 & 0 & 0 & 0 & 0 & 100 & 30.47 & 20.26 & 1030 \\
\hline 18 & 0.74 & 0 & 100 & 0 & 0 & 0 & 0 & 50 & 50 & 17.56 & 16.88 & 1101 \\
\hline 19 & 0.74 & 0 & 100 & 0 & 0 & 0 & 50 & 0 & 50 & 14.60 & 14.86 & 998 \\
\hline 20 & 0.46 & 0 & 100 & 0 & 0 & 0 & 33 & 33 & 33 & 39.01 & 21.18 & 998 \\
\hline 21 & 0.74 & 0 & 50 & 0 & 50 & 100 & 0 & 0 & 0 & 19.40 & 18.07 & 749 \\
\hline 22 & 0.46 & 0 & 50 & 0 & 50 & 0 & 0 & 100 & 0 & 42.18 & 18.69 & 881 \\
\hline 23 & 0.46 & 0 & 50 & 0 & 50 & 0 & 100 & 0 & 0 & 33.65 & 21.66 & 1004 \\
\hline 24 & 0.74 & 0 & 50 & 0 & 50 & 0 & 50 & 50 & 0 & 19.05 & 15.01 & 1242 \\
\hline 25 & 0.46 & 0 & 50 & 50 & 0 & 100 & 0 & 0 & 0 & 34.78 & 21.15 & 985 \\
\hline 26 & 0.74 & 0 & 50 & 50 & 0 & 0 & 0 & 100 & 0 & 26.03 & 14.39 & 1560 \\
\hline 27 & 0.74 & 0 & 50 & 50 & 0 & 0 & 100 & 0 & 0 & 16.79 & 13.18 & 1956 \\
\hline 28 & 0.46 & 0 & 50 & 50 & 0 & 0 & 50 & 50 & 0 & 35.13 & 18.70 & 1051 \\
\hline 29 & 0.74 & 0 & 33 & 33 & 33 & 0 & 0 & 0 & 100 & 14.67 & 12.06 & 1892 \\
\hline 30 & 0.46 & 0 & 33 & 33 & 33 & 0 & 0 & 50 & 50 & 31.11 & 17.12 & 1171 \\
\hline 31 & 0.46 & 0 & 33 & 33 & 33 & 0 & 50 & 0 & 50 & 27.23 & 16.64 & 1243 \\
\hline 32 & 0.74 & 0 & 33 & 33 & 33 & 0 & 33 & 33 & 33 & 18.62 & 14.15 & 1881 \\
\hline 33 & 0.60 & 0 & 50 & 25 & 25 & 0 & 33 & 33 & 33 & 25.04 & 16.77 & 1845 \\
\hline 34 & 0.60 & 0 & 0 & 50 & 50 & 0 & 33 & 33 & 33 & 23.42 & 14.51 & 1882 \\
\hline 35 & 0.60 & 0 & 25 & 50 & 25 & 0 & 33 & 33 & 33 & 23.70 & 13.07 & 1278 \\
\hline 36 & 0.60 & 0 & 50 & 0 & 50 & 0 & 33 & 33 & 33 & 25.96 & 16.68 & 1192 \\
\hline 37 & 0.60 & 0 & 25 & 25 & 50 & 0 & 33 & 33 & 33 & 23.49 & 16.21 & 1190 \\
\hline 38 & 0.60 & 0 & 50 & 50 & 0 & 0 & 33 & 33 & 33 & 24.90 & 16.00 & 1309 \\
\hline 39 & 0.60 & 0 & 33 & 33 & 33 & 0 & 50 & 25 & 25 & 23.63 & 16.12 & 1257 \\
\hline 40 & 0.60 & 0 & 33 & 33 & 33 & 0 & 0 & 50 & 50 & 26.10 & 15.62 & 1186 \\
\hline 41 & 0.60 & 0 & 33 & 33 & 33 & 0 & 25 & 50 & 25 & 26.59 & 14.98 & 1267 \\
\hline 42 & 0.60 & 0 & 33 & 33 & 33 & 0 & 50 & 0 & 50 & 23.56 & 16.24 & 1145 \\
\hline 43 & 0.60 & 0 & 33 & 33 & 33 & 0 & 25 & 25 & 50 & 23.35 & 15.85 & 1243 \\
\hline 44 & 0.60 & 0 & 33 & 33 & 33 & 0 & 50 & 50 & 0 & 27.86 & 15.68 & 1424 \\
\hline 45 & 0.80 & 0 & 33 & 33 & 33 & 0 & 33 & 33 & 33 & 17.35 & 13.55 & 1253 \\
\hline 46 & 0.40 & 0 & 33 & 33 & 33 & 0 & 33 & 33 & 33 & 36.54 & 19.70 & 1152 \\
\hline 47 & 0.60 & 0 & 33 & 33 & 33 & 0 & 33 & 33 & 33 & 23.77 & 15.54 & 1224 \\
\hline 48 & 0.60 & 0 & 33 & 33 & 33 & 0 & 33 & 33 & 33 & 21.22 & 16.16 & 1202 \\
\hline 49 & 0.46 & 25 & 25 & 25 & 25 & 25 & 25 & 25 & 25 & 34.85 & 21.07 & 944 \\
\hline 50 & 0.74 & 25 & 25 & 25 & 25 & 25 & 25 & 25 & 25 & 19.05 & 16.04 & 1015 \\
\hline
\end{tabular}


Table 3. Terminology for model variables.

\begin{tabular}{|c|c|c|}
\hline \multirow{2}{*}{ Term } & \multicolumn{2}{|l|}{ Variable } \\
\hline & Description & Type \\
\hline rmc & percentage of natural coarse aggregate replaced by recycled mortar coarse aggregate & Independent \\
\hline $\mathrm{rmf}$ & percentage of natural fine aggregate replaced by recycled mortar fine aggregate & Independent \\
\hline $\mathrm{rcc}$ & $\begin{array}{c}\text { percentage of natural coarse aggregate replaced by recycled concrete coarse } \\
\text { aggregate }\end{array}$ & Independent \\
\hline $\operatorname{rcf}$ & percentage of natural fine aggregate replaced by recycled concrete fine aggregate & Independent \\
\hline $\operatorname{rrcc}$ & $\begin{array}{c}\text { percentage of natural coarse aggregate replaced by recycled red ceramic coarse } \\
\text { aggregate }\end{array}$ & Independent \\
\hline $\operatorname{rrcf}$ & percentage of natural fine aggregate replaced by recycled red ceramic fine aggregate & Independent \\
\hline $\mathrm{w} / \mathrm{c}$ & water/cement ratio & Independent \\
\hline $\mathrm{f}_{\mathrm{c}}$ & compressive strength at 28 days & Dependent \\
\hline $\mathrm{E}_{\mathrm{c}}$ & modulus of elasticity at 28 days & Dependent \\
\hline$\varepsilon_{224}$ & drying shrinkage at 224 days & Dependent \\
\hline
\end{tabular}

$f_{c}=\left(\frac{b_{1}}{b_{2}{ }^{w / c}}\right) \cdot\left[1-\left(a_{1} \cdot r m c+a_{2} \cdot r m f+a_{3} \cdot r c c+a_{4} \cdot r c f+a_{5} \cdot r r c c+a_{6} \cdot r r c f\right)\right]$

$E_{c}=\left(\frac{b_{1}}{w / c^{0,5}}\right) \cdot\left[1-\left(a_{1} \cdot r m c+a_{2} \cdot r m f+a_{3} \cdot r c c+a_{4} \cdot r c f+a_{5} \cdot r r c c+a_{6} \cdot r r c f\right)\right]$

$\varepsilon_{224}=\left(b_{1} \cdot w / c^{0,5}\right) \cdot\left(1+a_{1} \cdot r m c+a_{2} \cdot r m f+a_{3} \cdot r c c+a_{4} \cdot r c f+a_{5} \cdot r r c c+a_{6} \cdot r r c f\right)$

Tables 4, 5 and 6 show parameter estimation for each regression model and the corresponding analysis of variance (ANOVA).

The coefficient of determination $\left(\mathrm{R}^{2}\right)$ computed by ANOVA indicates that models explain $96.5 \%, 96.6 \%$ and $60.4 \%$ of the variability observed in compressive strength, modulus of elasticity and drying shrinkage, respectively. Durbin-Watson statistics of all cases was superior to 1.4, which indicates that there are no serious problems of autocorrelation in the residuals. Once confidence intervals do not contain zero, it can be said that the terms included are significant considering the adopted confident levels.

Tests of normality of residuals were accomplished (Table 7), and in all cases the p-value was higher than 0.05 , so the hypothesis of normal distribution can not be rejected at the $95 \%$ confidence level. Thus, usual hypotheses of regression analysis are satisfied.

Following the results of the statistical analyses, the models obtained for compressive strength, modulus of elasticity and drying shrinkage are shown in Equations 4, 5 and 6 , respectively. These models were previously published by the authors ${ }^{33,34}$.

$f_{c}=\left(\frac{115}{7,2^{w / c}}\right) \cdot[1-(0,306 \cdot r m c+0,164 \cdot r m f+0,195 \cdot r c c+0,058 \cdot r c f+0,344 \cdot r r c c-0,136 \cdot r r c f)]$

$E_{c}=\left(\frac{21}{w / c^{0,5}}\right) \cdot[1-(0,344 . r m c+0,150 . r m f+0,214 . r c c+0,098 . r c f+0,438 . r r c c+0,102 . r r c f)]$

$\varepsilon_{224}=\left(675,4 . w / c^{0,5}\right) \cdot(1+0,442 . r m c+0,766 . r m f+0,597 . r c c+1,05 . r c f+0,581 . r r c c+0,602 . r r c f)$

Finally, using the proposed models, a performance estimation of recycled aggregate concretes was accomplished. For that, the average composition of the recycled aggregates of the CDW for some Brazilian cities: São Carlos, São Paulo, Porto Alegre, Ribeirão Preto, Salvador, Campina Grande and Maceió, was used (see Table 1). However, there are
Table 4. Parameter estimation and ANOVA for compressive strength.

\begin{tabular}{ccccc}
\hline & & \multicolumn{3}{c}{$\begin{array}{c}\text { Confidence } \\
\text { interval of 95\% }\end{array}$} \\
\hline Parameter & Estimator & $\begin{array}{c}\text { Standard } \\
\text { error }\end{array}$ & Lower & Upper \\
\hline b1 & 115.12 & 5.445 & 104.12 & 126.11 \\
b2 & 7.20 & 0.569 & 6.05 & 8.35 \\
a1 & 0.306 & 0.028 & 0.249 & 0.361 \\
a2 & 0.164 & 0.028 & 0.106 & 0.222 \\
a3 & 0.195 & 0.028 & 0.138 & 0.251 \\
a4 & 0.058 & 0.028 & 0.001 & 0.116 \\
a5 & 0.344 & 0.027 & 0.291 & 0.398 \\
a6 & -0.136 & 0.030 & -0.196 & -0.074 \\
\hline & \multicolumn{3}{c}{ ANOVA } & \\
\hline Source & Sum of & Degrees of & Mean & F test \\
& squares & freedom & square & \\
\hline Model & 36272.9 & 8 & 4534.11 & 1692.5 \\
Residual & 109.828 & 41 & 2.678 & \\
Total & 36382.7 & 49 & & \\
\hline
\end{tabular}

$\mathrm{R}^{2}=96.50 \%$; $\mathrm{p}$-value associated to $\mathrm{F}$ test $<0.0001$; Estimative standard error $=1.64 ;$ Durbin-Watson statistic $=1.98$

some components in Table 1 that are not considered in the proposed models. To deal with this fact, components proportion was recalculated, excluding the materials that were not contemplated in the models. The new compositions of recycled aggregates of CDW, considering only mortar, concrete and ceramic material as components, are shown in Table 8 .

Using the adjusted proportions, the values for each property (compressive strength, modulus of elasticity and drying shrinkage) were estimated using Equations 4, 5 and 6. Three concrete compositions were analyzed: concrete with $100 \%$ replacement of natural fine aggregate by fine recycled aggregates, concrete with $100 \%$ replacement of natural coarse aggregate by recycled coarse aggregates and concrete with $100 \%$ replacement of coarse and fine natural 
aggregate for their respective recycled aggregates. Besides the aggregate type, the water/cement ratio (w/c) was varied, in values of $0.45,0.60$ and 0.75 .

Table 5. Parameter estimation and ANOVA for modulus of elasticity.

\begin{tabular}{ccccc}
\hline & & \multicolumn{3}{c}{$\begin{array}{c}\text { Confidence } \\
\text { interval of 95\% }\end{array}$} \\
\hline Parameter & Estimator & $\begin{array}{c}\text { Standard } \\
\text { error }\end{array}$ & Lower & Upper \\
\hline b1 & 21.03 & 0.369 & 20.282 & 21.770 \\
a1 & 0.344 & 0.017 & 0.311 & 0.379 \\
a2 & 0.150 & 0.018 & 0.114 & 0.186 \\
a3 & 0.214 & 0.017 & 0.179 & 0.249 \\
a4 & 0.098 & 0.017 & 0.063 & 0.133 \\
a5 & 0.438 & 0.016 & 0.405 & 0.470 \\
a6 & 0.102 & 0.016 & 0.069 & 0.135 \\
\hline & \multicolumn{3}{c}{ ANOVA } & \\
\hline Source & Sum of & Degrees of & Mean & F test \\
& squares & freedom & square & \\
\hline Model & 13590.8 & 7 & 1941.54 & 3395.6 \\
Residual & 24.0143 & 42 & 0.572 & \\
Total & 13614.8 & 49 & & \\
\hline
\end{tabular}

$\mathrm{R}^{2}=96.60 \%$; p-value associated to $\mathrm{F}$ test $<0.0001$;Estimative standard error $=0.756 ;$ Durbin-Watson Statistic $=2.11$

Table 6. Parameter estimation and ANOVA for drying shrinkage.

\begin{tabular}{ccccc}
\hline & & \multicolumn{3}{c}{$\begin{array}{c}\text { Confidence } \\
\text { interval of 95\% }\end{array}$} \\
\hline Parameter & Estimator & $\begin{array}{c}\text { Standard } \\
\text { error }\end{array}$ & Lower & Upper \\
\hline b1 & 675.47 & 147.566 & 426.67 & 924.26 \\
a1 & 0.442 & 0.282 & 0.034 & 0.918 \\
a2 & 0.766 & 0.340 & 0.194 & 1.339 \\
a3 & 0.597 & 0.313 & 0.069 & 1.125 \\
a4 & 1.050 & 0.391 & 0.392 & 1.709 \\
a5 & 0.581 & 0.302 & 0.072 & 1.089 \\
a6 & 0.602 & 0.300 & 0.096 & 1.108 \\
\hline & \multicolumn{4}{c}{ ANOVA } \\
\hline Source & Sum of & Degrees of & Mean & F test \\
& squares & freedom & square & \\
\hline Model & $6.07 .10^{7}$ & 7 & 8683910 & 289.9 \\
Residual & $1.13 .10^{6}$ & 38 & 29956.8 & \\
Total & $6.192 .10^{7}$ & 45 & & \\
\hline
\end{tabular}

$\mathrm{R}^{2}=60.4 \%$; $\mathrm{p}$-value associated to $\mathrm{F}$ test $<0.0001$; Estimative standard error $=173.1 ;$ Durbin-Watson statistic $=1.77$

\section{Results and Discussion}

The results of concrete performance estimation are shown in Figures 1, 2 and 3, for compressive strength, modulus of elasticity and drying shrinkage, respectively.

According to Figure 1, it is observed that w/c ratio and type of aggregate govern the compressive strength. The lower the $\mathrm{w} / \mathrm{c}$ ratio, the higher the compressive strength, for all aggregate types. This result is coherent with other studies presented in literature $19,20,23,27$. Increasing the $w / c$ ratio from 0.45 to 0.6 and to 0.75 promote $25.6 \%$ and $44.7 \%$ reduction in compressive strength, respectively.

Concrete with recycled fine aggregates showed the highest compressive strength among all analyzed concretes, reaching average values of $45.7 \mathrm{MPa}, 34 \mathrm{MPa}$ and $25.3 \mathrm{MPa}$, for w/c ratio of $0.45,0.6$ and 0.75 , respectively. Using recycled coarse aggregates, concretes showed a $27.2 \%$ lower compressive strength, reaching average values of 33.2 MPa, 24.7 MPa and 18.4 MPa, for w/c ratio of 0.45 , 0.6 and 0.75 , respectively. The combined use of fine and coarse recycled aggregates provided concretes with similar strengths observed using coarse aggregate, around 30.8\% lower compressive strength than the one observed using fine aggregate. Average compressive strength of $31.6 \mathrm{MPa}$, $23.5 \mathrm{MPa}$ and $17.5 \mathrm{MPa}$, for w/c ratio of $0.45,0.6$ and 0.75 , respectively, were reached.

According to Figure 2, modulus of elasticity and compressive strength behaviors were similar. The influence of w/c ratio and type of aggregate is also noticeable. As would be expected, the higher the w/c ratio, the lower the modulus of elasticity, for all aggregate types. An increase in w/c ratio from 0.45 to 0.6 and to 0.75 decreases modulus of elasticity in $13.4 \%$ and $22.5 \%$, respectively. This behavior is coherent with other results presented in literature ${ }^{19,27}$.

Concretes with natural coarse aggregate and recycled fine aggregate present a modulus of elasticity average values of $27.5 \mathrm{GPa}, 23.8 \mathrm{GPa}$ and $21.3 \mathrm{GPa}$, for w/c ratio of 0.45 , 0.6 and 0.75 , respectively. For concretes with recycled coarse aggregates and natural fine aggregates, the modulus of elasticity decreases $26.2 \%$, reaching average values of 20.3 GPa, 17.6 GPa and 15.7 GPa, for w/c ratio of 0.45 , 0.6 and 0.75 , respectively. Using coarse and fine aggregates together, the average values of modulus of elasticity was $40.1 \%$ lower, reaching $16.5 \mathrm{GPa}, 14.3 \mathrm{GPa}$ and $12.8 \mathrm{GPa}$, for $w / c$ ratio of $0.45,0.6$ and 0.75 , respectively.

It can be observed that $w / c$ ratio has less influence on modulus of elasticity than on compressive strength. It seems also that type of aggregate has a stronger influence in modulus of elasticity than w/c ratio, although the use of $100 \%$ of coarse aggregate promotes the same percentage

Table 7. Normality tests of residuals.

\begin{tabular}{ccccccc}
\hline \multirow{2}{*}{ Test performed } & \multicolumn{2}{c}{ Compressive strength } & \multicolumn{2}{c}{ Modulus of elasticity } & \multicolumn{2}{c}{ Drying shrinkage } \\
\cline { 2 - 7 } & Test statistic & $\begin{array}{c}p \text { value } \\
\text { obtained }\end{array}$ & Test statistic & $\begin{array}{c}p \text { value } \\
\text { obtained }\end{array}$ & Test statistic & $\begin{array}{c}p \text { value } \\
\text { obtained }\end{array}$ \\
\hline Chi-Square goodness-of-fit & 8.6734 & 0.89396 & 18.959 & 0.2155 & 13.8 & 0.541 \\
Shapiro-Wilks W statistic & 0.97497 & 0.54977 & 0.9607 & 0.1749 & 0.957 & 0.143 \\
Z score for skewness & 1.0176 & 0.30883 & 0.4944 & 0.6209 & 1.108 & 0.268 \\
Z score for kurtosis & 0.91226 & 0.36162 & -0.1256 & 0.8999 & 1.562 & 0.118 \\
\hline
\end{tabular}


reduction on compressive strength and on modulus of elasticity. However, the use of both fine and coarse recycled aggregate promotes a stronger reduction on the modulus of elasticity than on the compressive strength. This probably occurs due to the fact that the modulus of elasticity is mainly guided by the aggregate. As the recycled aggregate is more deformable than the natural aggregate, recycled aggregate concretes become more deformable than conventional concretes $^{20}$.

For drying shrinkage, it is again observed the influence of both w/c ratio and type of aggregate, as shown in Figure 3. Once drying shrinkage is linked with water loss, the higher the water content in concrete, the larger the drying shrinkage ${ }^{20}$. So, increasing w/c ratio from 0.45 to 0.6 and to 0.75 increases drying shrinkage in $15.5 \%$ and $29.1 \%$, respectively.
Values obtained for concretes with recycled coarse aggregate are the smallest, presenting average values of 690, 797 and 891 micro for w/c ratio of $0.45,0.6$ and 0.75 , respectively. Concretes with recycled fine aggregate showed shrinkage average values $15.8 \%$ larger, reaching 799, 923 and 891 micro for w/c ratio of $0.45,0.6$ and 0.75 , respectively. For concretes combining fine and coarse recycled aggregate, drying shrinkage showed the greatest values, $50.1 \%$ larger than drying shrinkages of recycled coarse aggregate concrete, reaching average values of 1036, 1196 and 1337 micro for w/c ratio of $0.45,0.6$ and 0.75 , respectively.

Since the water absorption of recycled aggregates is relatively high, put more recycled aggregates in concrete mixtures means that more water will be necessary to maintain the same workability. So it is coherent that

Table 8. Adjusted composition of recycled aggregates of CDW, considering only mortar, concrete and ceramic material as components.

\begin{tabular}{ccccccccc}
\hline Components & $\begin{array}{c}\text { São Carlos } \\
(\boldsymbol{\%})\end{array}$ & $\begin{array}{c}\text { São Paulo } \\
(\boldsymbol{\%})\end{array}$ & $\begin{array}{c}\text { Porto Alegre } \\
(\boldsymbol{\%})\end{array}$ & $\begin{array}{c}\text { Ribeirão Preto } \\
(\boldsymbol{\%})\end{array}$ & $\begin{array}{c}\text { Salvador* } \\
(\boldsymbol{\%})\end{array}$ & $\begin{array}{c}\text { Campina Grande } \\
(\boldsymbol{\%})\end{array}$ & $\begin{array}{c}\text { Maceió } \\
(\boldsymbol{\%})\end{array}$ \\
\hline Mortar & 65.5 & 40 & 45.1 & 47.2 & 42.7 & 38.9 & 29.4 \\
Concrete & 4.5 & 13 & 18.6 & 26.6 & 42.7 & 13.9 & 19.7 \\
Ceramic materials & 30.0 & 47 & 36.3 & 26.2 & 14.6 & 47.2 & 50.9 \\
\hline
\end{tabular}

*A percentage of $26.5 \%$ of concrete and $26.5 \%$ of mortar were used in the initial proportion.

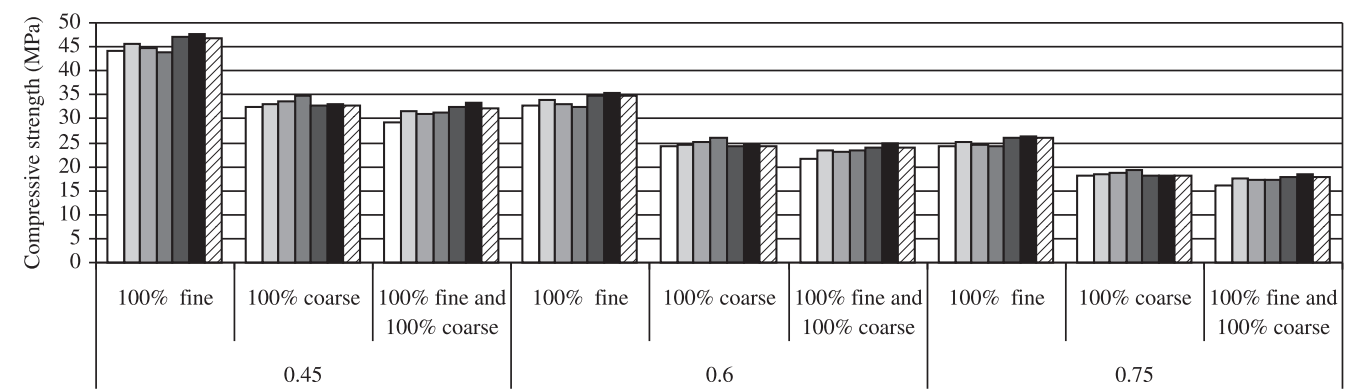

Water/cement ratio and recycled aggregate content

\section{$\square$ São Carlos/SP $\square$ Porto Alegre/RS $\square$ Ribeirão Preto/SP $\square$ Salvador/BA $\square$ Campina Grande/PB $\square$ Maceió/AL $\square$ São Paulo/SP}

Figure 1. Compressive strength estimation for concretes with recycled aggregates of CDW of some Brazilian cities.

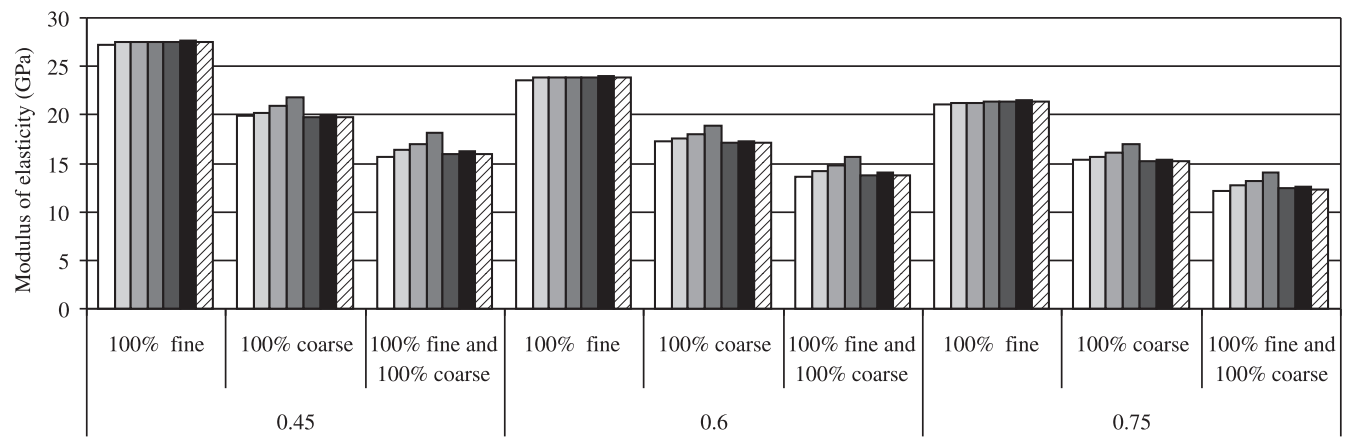

Water/cement ratio and recycled aggregate content

$\square$ São Carlos/SP $\square$ Porto Alegre/RS $\square$ Ribeirão Preto/SP $\square$ Salvador/BA $\square$ Campina Grande/PB $\square$ Maceió/AL $\square$ São Paulo/SP

Figure 2. Modulus of elasticity estimation for concretes with recycled aggregates of CDW of some Brazilian cities. 


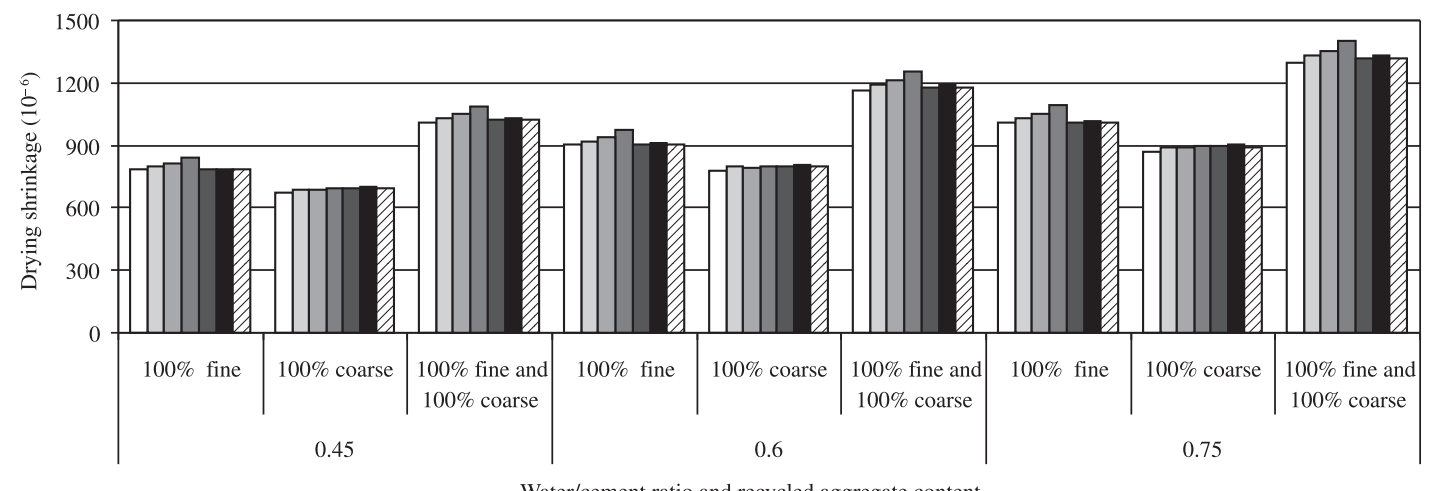

Water/cement ratio and recycled aggregate content

Figure 3. Drying shrinkage estimation for concretes with recycled aggregates of CDW of some Brazilian cities.

concretes with both fine and coarse recycled aggregate present the largest drying shrinkage.

For all analyzed properties, concretes with the same w/c ratio and type and content of recycled aggregate showed similar behavior, independently of the city where recycled aggregates comes from. However, analyzing the CDW composition of these cities, large variability is observed. Exemplifying, according to Table 4 data, mortar content in CDW varied from $29.4 \%$ in Maceió to $65.5 \%$ in São Carlos, while concrete content varied from $4.5 \%$ in São Carlos to $42.7 \%$ in Salvador, and ceramic material from $14.6 \%$ in Salvador to $50.9 \%$ in Maceió.

However, this pronounced variability does not have a strong influence in concrete properties. For example, according to Figure 1, comparing compressive strength of concretes with $100 \%$ of fine recycled aggregate and same $\mathrm{w} / \mathrm{c}$ ratio, the maximum difference obtained among strengths (comparing among cities) is $9.2 \%$. The same comparison for $100 \%$ coarse recycled aggregate and $100 \%$ fine and coarse aggregates reveals maximum differences on strength of $7 \%$ and $14.2 \%$, respectively.

A similar analysis for the modulus of elasticity (Figure 2) reveals that the maximum differences obtained among cities for this property are $2.1 \%, 11 \%$ and $15.3 \%$, for concretes with $100 \%$ of fine recycled aggregate, $100 \%$ of coarse recycled aggregate and $100 \%$ of fine and coarse aggregates, respectively. Finally, for drying shrinkage (Figure 3 ) the maximum differences obtained are 8\%, 3.5\% and $7.7 \%$, for respectively concretes previously mentioned. This means that CDW composition, and consequently recycled aggregate composition, has little influence into compressive strength, modulus of elasticity and drying shrinkage of recycled aggregate concrete.

Although, it is worth noting that the estimation presented here were not experimentally proven. There are details concerning the used aggregates, like size distribution, absorption and density, and concerning used cement, like type and content of pozzolan or cement material, which are not contemplated by the proposed models. These are aspects that have influence on the measured properties. So, for project or building execution consideration, tests must be performed to assure the desired mechanical and durability concrete properties.

\section{Conclusions}

According to the results obtained using regression models to study the scenario of some Brazilian cities, we concluded that the use of recycled aggregates of CDW in concrete production is quite feasible. Compressive strength and modulus of elasticity of these concretes reached considerable values, mainly when fine recycled aggregate is used. Results reveal that the use of recycled aggregate should be prioritized into concretes with low w/c ratio, once it produces concretes with lower drying shrinkage, repressing fissures and increasing structure durability.

It was also noticed that the variability of recycled aggregate composition did not cause large differences in values obtained for compressive strength, modulus of elasticity and drying shrinkage. So, we concluded that the variability presented by recycled aggregates of CDW does not compromise their use for concrete building. However, this information must be used with caution, and experimental tests should always be performed to certify concrete properties.

\section{Acknowledgements}

The authors thank to NORIE (Nucleus Guided to the Innovation of the Construction) of UFRGS and GPMATE (Structures and Construction Materials Research Group) of UFC for the support in the accomplishment of the experiments, to CNPq for the scholarship concession and to CAPES for financing this work through PQI 106/08-03. 


\section{References}

1. Quadros BEC and Oliveira AMV. Differentiated management of the rubble in the city of Salvador. In: Carneiro AP, Brum IAS and Cassa JCS, editors. Rubble recycing for construction materials production. Salvador: EDUFBA; 2001. 312 p., p. 116-141. (in Portuguese).

2. Poon CS, Ann TWY and Ng LH. On site sorting of construction and demolition waste in Hong Kong. Resources, Conservation and Recycling. 2001; (32):157-172. http://dx.doi.org/10.1016/ S0921-3449(01)00052-0

3. Pinto TP. Methodology for differentiated management of solid waste of urban construction. [Thesis]. São Paulo: Polytechnic University of Sao Paulo; 1999. 203 p. (in Portuguese).

4. Freitas CS, Correia RF, França KP, Santana FG and Leite MB. Diagnosis of illegal disposal of construction and demolition waste of Feira de Santana/BA: pilot study. In: Proceedings of the VI Seminar on Sustainable Development and Construction Recycling; 2003; São Paulo. São Paulo: IBRACON; 2003. CT-206. (in Portuguese).

5. Sardá MC and Rocha JC. Methods for classification and reduction of construction waste taken in Blumenau/SC, based on the resolution 307 of CONAMA. In: Proceedings of the VI Seminar on Sustainable Development and Construction Recycling; 2003; São Paulo. São Paulo: IBRACON; 2003. CT-206. (in Portuguese).

6. Marques Neto JC. Management of construction and demolition wastes in Brazil. São Carlos: Rima; 2005. 162 p. (in Portuguese).

7. Solis-Guzman J, Marrero M, Montes-Delgado M and Ramirez-De-Arellano AA. Spanish model for quantification and management of construction waste. Waste Management. 2009; 29:2542-2548. PMid:19523801. http:// dx.doi.org/10.1016/j.wasman.2009.05.009

8. Sonigo P, Hestin M and Mimid S. Management of construction and demolition waste in Europe. In: Proceedings of the Stakeholders Workshop; 2010; Brussels. Brussels; 2010.

9. Sáez PV, Merino MR, Amores CP and González ASA. European Legislation and Implementation Measures in the Management of Construction and Demolition Waste. The Open Construction and Building Technology Journal. 2011; (5):156-161.

10. Hansen TC. Recycled aggregates and recycled aggregate concrete: third state-of-the-art report 1945-1989. In: Hansen TCE and Spon FN, editors. Recycling of Demolished Concrete and Masonry. London: RILEM; 1992. p. 1-163. RILEM Technical Committee Report, n. 6.

11. Cochran KM and Townsend TG. Estimating construction and demolition debris generation using a materials flow analysis approach. Waste Management. 2010; (30):2247-2254. PMid:20472418.

12. Esin T and Cosgun N. A study conducted to reduce construction waste generation in Turkey. Building and Environment. 2007; (42):1667-1674. http://dx.doi. org/10.1016/j.buildenv.2006.02.008

13. Téchne: Construction Technology Magazine. São Paulo: Ed. Pini; 2001. v. 10, issue 55, 96 p. (in Portuguese).

14. Henrichsen A. Use of recycled aggregate. In: Proceeding of the International Workshop on Recycled Aggregate; 2000; Niigata. Niigata; 2000. p. 1-8.

15. Begun RA, Siwar C, Pereira JJ and Jaafar AH. A benefit-cost analysis on the economic feasibility of construction waste minimization: the case of Malaysia. Resources, Conservation and Recycling. 2006; (48):86-98. http://dx.doi.org/10.1016/j. resconrec.2006.01.004

16. Kartam N, Al-Mutairi N, Al-Ghusain I and Al-Humound J. Environmental management of construction and demolition waste in Kuwait. Waste Management. 2004; (24):1049-1059. Pmid:15567670. http://dx.doi.org/10.1016/j. wasman.2004.06.003

17. Pinto TP. Use of construction waste: study of the use in mortars. [Thesis]. São Carlos: University of Sao Paulo; 1986. 140 p. (in Portuguese).

18. Brito Filho JA. Cities versus Rubble. In: Proceedings of the Seminar on Sustainable Development and Construction Recycling; 1999; São Paulo. São Paulo: IBRACON Technical Committee; 1999. p. 56-67. CT 206 - Environmental.

19. Lovato PS. Verification of control parameters of recycled aggregates from construction and demolition waste for use in concrete. [Thesis]. Porto Alegre: Federal University of Rio Grande do Sul; 2007. 180 p. (in Portuguese).

20. Zordan SE. Use the debris as aggregate to make concrete. [Thesis]. Campinas: State University of Campinas; 1997. 140 p. (in Portuguese).

21. Nóbrega ARS. Contribution to diagnosis of the generation of construction rubble in Campina Grande, PB.[Thesis]. Campina Grande: Federal University of Paraíba; 2002. (in Portuguese).

22. Vieira GL. Study of the corrosion process under the action of chloride ions in concrete made from recycled aggregates from construction and demolition waste. [Thesis]. Porto Alegre: Federal University of Rio Grande do Sul; 2003. 151 p. (in Portuguese).

23. Souza UEL, Agopyan V, Paliari JC and Andrade AC. Waste Materials in Construction Sites Construction: Breaking the Myth. In: Proceedings of the Nacional Symposium; 1999; São Paulo. São Paulo: PCC/EPUSP; 1999. (in Portuguese).

24. Van Acker A. Recycling of Concrete at a Precast Concrete Plant. Paris: BIBM; 1996. p. 55-67.

25. Hansen CT and Boegh E. Elasticity and drying shrinkage of recycled-aggregate concrete. ACI Journal. 1985; 82:19-26.

26. American Concrete Institute Committee 555. Removal and reuse of hardened concrete. ACI Materials Journal. 2002; May-June:300-325.

27. Leite MB. Evaluation of mechanical properties of concrete produced with recycled aggregates from construction and demolition waste. [Thesis]. Porto Alegre: Federal University of Rio Grande do Sul; 2001. 270 p. (in Portuguese).

28. Ribeiro JLD and Caten CST. Design of experiments. Porto Alegre: FEEng/UFRGS; 2001. 128 p. (in Portuguese).

29. Lin Y, Tyan Y, Chang T and Chang C. An assessment of optimal mixture for concrete made with recycled concrete aggregates. Cement and Concrete Research. 2004; 34:1373-1380. http:// dx.doi.org/10.1016/j.cemconres.2003.12.032

30. Brazilian Association of Technical Standards - ABNT. NBR 5739: Concrete: compression test of cylindrical specimens - Method of test. Rio de Janeiro: ABNT; 2007. (in Portuguese)

31. Brazilian Association of Technical Standards - ABNT. NBR 8522: Concrete: determination of elasticity modulus by compression. Rio de Janeiro: ABNT; 2008. (in Portuguese)

32. American Society for Testing and Materials - ASTM. C 157: Standard test method for length change of hardened hydraulic-cement mortar and concrete. West Conshohocken: ASTM; 1993.

33. Cabral AEB, Schalch V, Dal Molin DCC, Ribeiro JLD and Ravindrarajah RS. Shrinkage modeling of recycled aggregate concrete. Ibracon Journal of Structures and Materials (RIEM). 2010; 3:1-23.

34. Cabral AEB, Schalch V, Dal Molin DCC and Ribeiro JLD. Mechanical properties modeling of recycled aggregate concrete. Construction \& Building Materials. 2010; 24:421-430. http:// dx.doi.org/10.1016/j.conbuildmat.2009.10.011 